\title{
Pesquisa-ação: ferramenta metodológica para a pesquisa qualitativa
}

\author{
Action-research: a methodological tool for qualitative research
}

\section{I nvestigación-acción: herramienta metodológica para la investigación cualitativa}

\author{
Magda Santos Koerich', Dirce Stein Backes"', Francisca Georgina Macêdo de Sousa"I', Alacoque Lorenzini
} Erdmann IV , Gelson Luiz Alburquerque ${ }^{\mathrm{V}}$

\footnotetext{
Enfermeira. Mestre em Enfermagem. Doutoranda do Programa de Pós-Graduação em Enfermagem da Universidade Federal de Santa Catarina (PEN/UFSC). Professora Assistente 3 do Departamento de Patologia da UFSC. E-mail: mskoerich@ccs.ufsc.br.

"Enfermeira. Mestre em Enfermagem. Doutoranda do PEN/UFSC. E-mail: backesdirce@ig.com.br.

II' Enfermeira. Mestre em Enfermagem. Doutoranda do PEN/UFSC. Docente do Curso de Enfermagem da Universidade Federal do Maranhão. Bolsista do CNPq. E-mail: fgeorginams@hotmail.com.

IV Enfermeira. Doutora em Filosofia da Enfermagem. Professora Titular da UFSC. Pesquisadora do CNPq. E-mail: alacoque@newsite.com.br.

$\checkmark$ Enfermeiro. Doutor em Filosofia da Enfermagem. Professor Titular da UFSC. E-mail: gelsonalbuquerque@yahoo.com.br.
}

\section{RESUMO}

A pesquisa-ação é um tipo de pesquisa interpretativa que abarca um processo metodológico empírico. Compreende a identificação do problema dentro de um contexto social e/ou institucional, o levantamento de dados relativos ao problema, à análise e significação dos dados levantados pelos participantes, a identificação da necessidade de mudança, o levantamento de possíveis soluções e por fim, a intervenção e/ou ação propriamente dita no sentido de aliar pesquisa e ação, simultaneamente. Face a pouca utilização dessa metodologia nas práticas de saúde, esse estudo tem por objetivo refletir e apresentar a pesquisa-ação enquanto uma importante ferramenta metodológico-gerencial capaz de aliar teoria e prática por meio de uma ação que visa a transformação de uma determinada realidade.

Descritores: Ciência. Metodologia. Pesquisa qualitativa.

\section{ABSTRACT}

Action-research is a type of interpretative research that involves an empirical methodological process that comprehends the identification of the problem within a social and/or institutional context, the collection of data related to the problem, the analysis and signifying of the data collected, the identification of the need for change, the raising of possible solutions and the actual intervention and/or action in the sense of allying research and action simultaneously. Once this methodology is rarely used in Health practices, this study aims to reflect and present action research as an important methodological tool capable of allying theory and practice through an action that aims for the transformation of a specific reality.

Descriptors: Science. Methodology. Qualitative research.

\section{RESUMEN}

Action-research is a type of interpretative research that involves an empirical methodological process that comprehends the identification of the problem within a social and/or institutional context, the collection of data related to the problem, the analysis and signification of the data collected, the identification of the need for change, the raising of possible solutions and the actual intervention and/or action in the sense of allying research and action simultaneously. Once this methodology is rarely used in Health practices, this study aims to reflect and present action research as an important methodological tool capable of allying theory and practice through an action that aims for the transformation of a specific reality.

Descriptores: Ciencia. Metodología. Investigación Cualitativa. 


\section{CONSI DERAÇÕES PRELI MI NARES}

Desmistificar crenças, inovar estratégias gerenciais, organizacionais e de pesquisa, problematizar as práticas de cuidado pautadas pelo saber tradicional na saúde/enfermagem, possibilitar ferramentas para a transformação do ensino e das práticas na saúde foram, entre outros, elementos de análise e reflexão individual e/ou grupal estabelecidos no Grupo de Estudos e Pesquisas em Administração de Enfermagem e Saúde (GEPADES), junto ao Programa de Pós-Graduação em Enfermagem da Universidade Federal de Santa Catarina.

Tais reflexões têm nos estimulado e provocado, crescentemente, enquanto docentes e discentes a produzir novos olhares sobre o panorama da saúde, da enfermagem e das práticas em geral nas quais nos incluímos espontaneamente e/ou somos incluídos por forças externas. Dentre a multiplicidade de enfoques metodológicos, a pesquisa-ação emergiu tanto como ferramenta de inclusão dos sujeitos quanto como possibilidade de transformação das práticas de saúde. Entendemos ser esta uma importante metodologia por aliar pesquisa e ação simultaneamente, ou seja, academia e prática como via de mão dupla.

As abordagens de pesquisa podem ser sintetizadas em duas grandes linhas, a positivista e a interpretativista. A primeira está relacionada às ciências duras e a segunda, pode ser enquadrada às várias metodologias relacionadas às ciências humanas, dentre elas: a pesquisa participante, a pesquisa com abordagem sócio-histórica, a pesquisa com abordagem fenomenológica, a pesquisa-ação, entre outras ${ }^{(1-2)}$

Nessa perspectiva, a pesquisa-ação é caracterizada como um tipo de pesquisa social com base empírica, concebida e realizada em estreita associação com uma ação ou com a resolução de um problema coletivo no qual os pesquisadores e os participantes, representativos da situação e/ou do problema, estão envolvidos de forma cooperativa e participativa $^{(3-5)}$.

A pesquisa-ação visa fornecer aos pesquisadores e grupos sociais os meios de se tornarem capazes de responder com maior eficiência aos problemas da situação em que vivem, em particular sob a forma de estratégias de ação transformadora e, ainda, facilitar a busca de soluções face aos problemas para os quais os procedimentos convencionais têm contribuído pouco.

Por compreender um movimento circular de compartilhamento, de subjetivação e de participação coletiva, como representado no diagrama abaixo, a pesquisa-ação tende a se impor, gradativamente, como um importante método de pesquisa na saúde e em outros setores sociais que intentam provocar transformações por meio da pesquisa e da ação simultaneamente.

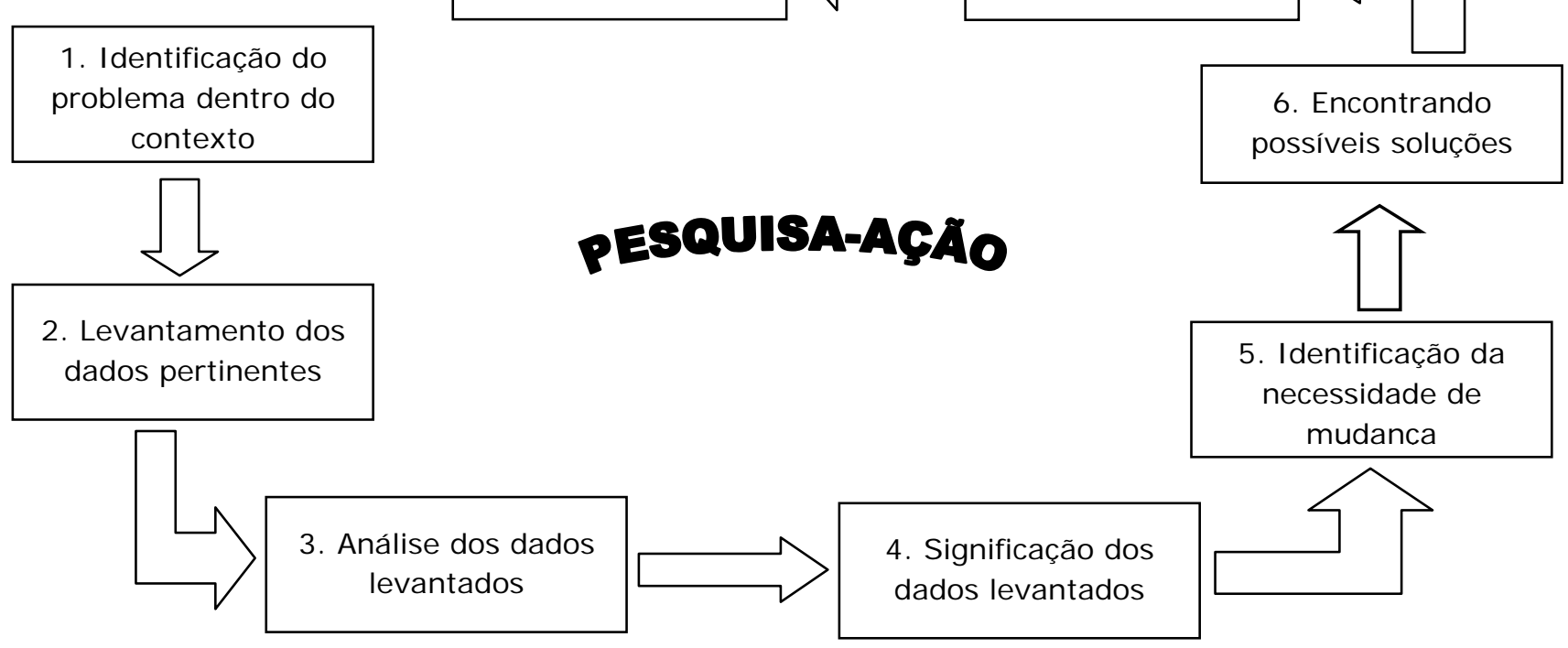

Figura 1: Elaboração primária a partir das abstrações teóricas ${ }^{(4-6)}$.

A pesquisa-ação, em outras palavras, abarca um processo empírico que compreende a identificação do problema dentro de um contexto social e/ou institucional, o levantamento de dados relativos ao problema e, a análise e significação dos dados levantados pelos participantes. Além da identificação da necessidade de mudança e o levantamento de possíveis soluções, a pesquisa-ação intervém na 
prática no sentido de provocar a transformação. Coloca-se então, como uma importante ferramenta metodológica capaz de aliar teoria e prática por meio de uma ação que visa à transformação de uma determinada realidade.

A pesquisa-ação permite associar ao processo de investigação a possibilidade de aprendizagem, pelo envolvimento criativo e consciente tanto do pesquisador como dos demais integrantes ${ }^{(7)}$. Daí sua importância, na área da saúde e enfermagem, como instrumento, ao mesmo tempo, de educação, investigação e mudança, podendo ser utilizada com diversos grupos: profissionais, gestores, estudantes e população em geral, tanto nas comunidades quanto em instituições.

Considerando a importância atribuída à pesquisa interpretativista, especialmente à pesquisa-ação, como possibilidade de intervir na realidade de diferentes grupos sociais, buscamos informações, no banco de dissertações e teses da Coordenação de Aperfeiçoamento de Pessoal de Nível Superior (CAPES), na intenção de identificar sua utilização na área da saúde e Enfermagem. Localizamos os trabalhos desenvolvidos entre 2003 e 2007, a partir dos descritores: pesquisa-ação em saúde; pesquisaação em enfermagem e; pesquisa-ação e educação popular. Assim, para o primeiro descritor foram encontradas duas teses e uma dissertação; com o segundo, dezessete teses e nenhuma dissertação; enquanto o terceiro mostrou apenas uma tese. Isso indica uma utilização, ainda escassa, dessa metodologia de pesquisa na área da saúde e coloca a Enfermagem como o campo do saber em saúde que mais se apropria da pesquisa-ação para produção de conhecimentos, aliando pesquisa e prática.

Outro aspecto interessante na busca por estudos que utilizaram pesquisa-ação na Enfermagem foi a imensa concentração deles (77\%) em uma única instituição, a Universidade de São Paulo, apontando para a necessidade de maior divulgação dessa metodologia. Destaca-se que essa informação é restrita às teses e dissertações catalogadas na CAPES sem considerar consulta às publicações na forma de artigos científicos.

Assim, esse estudo tem por objetivo refletir e apresentar a pesquisa-ação, a fim de divulgá-la como ferramenta metodológica para utilização na área da saúde, especialmente na Enfermagem, quando se busca produzir conhecimentos e intervir na realidade.

\section{CONTEXTUALIZANDO A PESQUISA-AÇÃO COMO FERRAMENTA METODOLÓGI CA}

A pesquisa-ação teve origem com os trabalhos de Kurt Lewin ${ }^{(8)}$ em 1946, ao qual se atribui também a autoria do termo ${ }^{(9)}$. Os traços especiais da pesquisa-ação estão relacionados a conceituação de problemas, o planejamento, a execução e a avaliação de ações para resolvê-los, seguida da repetição desse ciclo de atividades ${ }^{(10)}$. Além da contribuição social, o trabalho de Lewin sobre pesquisa-ação foi considerado inovador por seu caráter participativo e democrático, já que a pesquisa se desenvolve com a participação dos sujeitos estudados e orientada, portanto, para a resolução de problemas nos ambientes onde eles ocorrem ${ }^{(11-12)}$. Ressalta-se a preocupação com a validade científica dos resultados da pesquisa, ao considerar os diagnósticos da situação antes e depois das ações, bem como o registro detalhado dos acontecimentos ${ }^{(12)}$.

A compreensão do modelo de pesquisa-ação relaciona-se a dois conceitos: o ato de investigação e o ato substantivo. O ato de investigação corresponde a uma ação que impulsiona uma indagação, enquanto o ato substantivo é a ação que promove uma mudança desejável no contexto estudado, ou seja, na investigação-ação, as ações são necessariamente atos substantivos. Isto é, o ato de investigar pressupõe uma obrigação de beneficiar pessoas que não pertencem à comunidade científica ${ }^{(12)}$.

A partir de Lewin, a pesquisa-ação tem sido utilizada de diferentes maneiras e diferentes intencionalidades, compondo um vasto mosaico de abordagens teórico-metodológicas, o que torna importante refletir sobre sua essencialidade epistemológica, bem como sobre suas possibilidades como práxis investigativa(3).

Os estudos de Franco $^{(5)}$ identificaram pelo menos três conceituações diferentes de pesquisa-ação no Brasil, classificadas como sendo: Pesquisa-ação colaborativa, quando a busca de transformação é solicitada pelo grupo de referência à equipe de pesquisadores. A função do pesquisador, nesse processo, será a de fazer parte e cientificizar um processo de mudança anteriormente desencadeado pelos sujeitos do grupo; Pesquisa-ação crítica, se, a partir dos trabalhos iniciais do pesquisador com o grupo, é percebida a necessidade de transformação. Quando ela é decorrente de um processo que valoriza a construção cognitiva da experiência, sustentada por reflexão crítica coletiva, com vistas à emancipação dos sujeitos e das condições que o coletivo considera opressivas, a pesquisa vai assumindo o caráter de criticidade; Pesquisa-ação estratégica, se, ao contrário, a transformação é previamente planejada, sem a participação dos sujeitos, e apenas o pesquisador acompanhará os efeitos e avaliará os resultados de sua aplicação. Aqui a pesquisa perde o qualificativo de pesquisa-ação crítica.

A condição para ser pesquisa-ação crítica requer um mergulho na práxis do grupo social em estudo, do qual se extraem as perspectivas latentes e o não familiar que sustenta as práticas, sendo as mudanças negociadas e geridas no coletivo. Nessa direção, a pesquisa-ação colaborativa, na maioria das vezes, assume também o caráter de criticidade ${ }^{(4-5)}$

A criticidade da pesquisa-ação pressupõe um 
processo de reflexão coletiva, acerca das estratégias operacionais a serem adotadas, uma vez que esta considera a voz do sujeito e suas perspectivas não apenas para o registro e posterior interpretação, mas como parte da tessitura da metodologia da investigação. Nesse caso, a metodologia não se estabelece por meio das etapas lineares de um método propriamente dito, mas se organiza a partir das situações relevantes que emergem do processo. Daí a ênfase no caráter formativo dessa modalidade de pesquisa, visto que o sujeito deve tomar consciência das transformações que vão ocorrendo em si próprio e no processo. Por este motivo a pesquisa-ação assume o caráter emancipatório, no qual os sujeitos da pesquisa passam a ter a possibilidade de se libertarem dos mitos e preconceitos que organizam suas defesas em relação às mudanças desejadas ${ }^{(13)}$.

A pesquisa-ação sofreu, ao longo dos anos, influências positivistas, pela incorporação da dialética da realidade social e os fundamentos de uma racionalidade crítica linear. Nessa perspectiva, o estatuto epistemológico de investigação da pequisaação voltou-se à questão da transformação social, agora referendada com compromissos éticos e políticos, com vistas à emancipação dos sujeitos e das condições que obscurecem esse processo emancipatório; configurada por abordagens interpretativas de análise; estruturada sob forma de participação crítica, cujo processo de pesquisa deverá permitir reconstruções e reestruturação de significados e caminhos em todo desenrolar do processo, enquadrando-se num procedimento essencialmente pedagógico e político ${ }^{(4-5)}$.

$\mathrm{Na}$ perspectiva da pesquisa qualitativa, apresentam-se três dimensões a serem consideradas na pesquisa-ação, quais sejam: "a ontológica, referente à natureza do objeto a ser conhecido; a epistemológica, referente à relação sujeitoconhecimento e a metodológica, referente a processos de conhecimento utilizados pelo pesquisador"(5).

A dimensão ontológica refere-se a um conhecimento norteador que deve permitir aos sujeitos produzirem conhecimentos para uma melhor compreensão dos condicionantes da práxis; para estabelecer mudanças em suas práticas profissionais; para a melhoria das práticas; para fins coletivamente desejados e para produzirem conhecimentos para a reestruturação de processos formativos.

A dimensão epistemológica requer, para o seu exercício, um mergulho na intersubjetividade da dialética do coletivo. É preciso que o pesquisador assuma uma postura diferenciada diante do conhecimento, uma vez que este busca, ao mesmo tempo, conhecer e intervir na realidade que pesquisa. Essa imbricação entre pesquisa e ação faz com que o pesquisador, inevitavelmente, faça parte do universo pesquisado o que, de alguma forma, anula a possibilidade de uma postura de neutralidade e de controle das circunstâncias de pesquisa. São pressupostos epistemológicos fundamentais: a priorização da dialética da realidade social, da historicidade dos fenômenos, da práxis, das contradições, das relações com a totalidade e da ação dos sujeitos sobre suas circunstâncias; a práxis deve ser concebida como mediação básica na construção do conhecimento, pois por meio dela se veicula teoria e prática. O conhecimento não se restringe à mera descrição, mas busca o explicativo a partir do observável e por meio dos movimentos dialéticos do pensamento e da ação. Nessa expectativa, o saber produzido é necessariamente transformador dos sujeitos e das circunstâncias.

A dimensão metodológica exige procedimentos articuladores da ontologia com a epistemologia da pesquisa-ação que instaurem, no grupo, uma dinâmica de princípios e práticas dialógicas, participativas e transformadoras. Nessa dimensão devem ser observados aspectos, tais como: a práxis social é ponto de partida e de chegada na construção/ressignificação do conhecimento; o processo de conhecimento se constrói nas múltiplas articulações com a intersubjetividade; a pesquisa-ação deve ser realizada no ambiente natural da realidade a ser pesquisada; a flexibilidade de procedimentos é fundamental e a metodologia deve permitir ajustes e caminhar de acordo com as sínteses provisórias que vão se estabelecendo no grupo; o método deve contemplar o exercício contínuo de espirais cíclicas que compreendem planejamento, ação, reflexão, pesquisa, ressignificação e replanejamento, quando necessário.

Na pesquisa-ação o processo de investigação, de educação e de ação acontecem concomitantemente. Por razões epistemológicas e metodológicas, o conhecimento é produzido quando os sujeitos participam ativamente do processo de investigação. Desse modo, a investigação leva ao saber e este ao poder, instigando as mudanças na realidade por meio da ação $^{(6)}$.

Nesse processo, o pesquisador depara-se, frequentemente, com alguns questionamentos, dentre eles: como se colocar numa cultura com códigos, significados, representações, resistências, expectativas, por certo variados e dissonantes? Como tornar familiar um ambiente tão novo, do qual, a princípio, o pesquisador não é um de seus componentes? Como adentrar e lidar com as contradições iniciais, como percebê-las? Como fazer dos grupos ali presentes equipe de trabalho? Como começar um trabalho de equalizar resistências? Como alcançar confiança e cumplicidade no grupo de trabalho?

Além dos elementos já pontuados, uma questão 
mais ampla que se coloca é a da necessária interpenetração de papéis, ou seja, como passar de pesquisador a participante, continuando a ser prioritariamente pesquisador, ou como passar de sujeito de pesquisa a pesquisador de seu fazer, mantendo-se prioritariamente no seu papel?

Nesse processo, há que se considerar que a pesquisa-ação não se realiza em um curto espaço de tempo. A imprevisibilidade é um componente fundamental à prática da pesquisa-ação. Considerar a imprevisibilidade significa estar aberto para as reconstruções, para as retomadas de princípio, para a recolocação de prioridades por meio de acordos consensuais e amplamente negociados ${ }^{(4)}$.

O percurso requer, igualmente, o registro rigoroso e metódico dos dados. Esse trabalho precisa ser realizado constantemente, sendo necessário um diário de campo, ou seja, um instrumento capaz de consignar os dados recolhidos durante todo o processo de pesquisa, de forma a objetivar o vivido e o compreendido. A dinâmica de coletar os dados e registrá-los coletivamente, discuti-los e contextualizá-los, é o caminho para a construção de novos saberes e/ou teorias científicas. Esse processo, entendido como compartilhamento dialético possibilita a produção de conhecimentos novos e contribui na formação de sujeitos críticos e reflexivos.

O planejamento da pesquisa-ação deve necessariamente compreender a flexibilidade e a circularidade, uma vez que a mesma não pressupõe as fases ordenadas e lineares das metodologias positivistas. No entanto, são destacados alguns momentos que poderão auxiliar no desenvolvimento do processo ${ }^{(3-6)}$, tais como:

a) Fase exploratória: é a fase em que se realiza o diagnóstico da realidade e onde se estabelece um primeiro levantamento da situação, dos problemas de primeira ordem, e das eventuais ações. A partir daí, pesquisadores e participantes se dedicam a estabelecerem os principais objetivos da pesquisa, os quais devem estar interligados ao campo de observação, aos atores e ao tipo de ação que se pretende focalizar no processo investigativo.

b) O tema da pesquisa: é definido a partir de um problema prático e da área de conhecimento a ser abordada. É escolhido com base em compromissos assumidos entre a equipe de pesquisadores e os sujeitos da situação investigada ou, pode também, ser solicitado pelos atores da situação. Deve interessar tanto aos pesquisadores como aos sujeitos investigados, para que todos desempenhem um papel ativo no desenvolvimento da pesquisa. Nesse momento, um marco teórico específico é escolhido para nortear a pesquisa.

c) A colocação dos problemas: é o momento em que é definida uma problemática na qual o tema escolhido ganhe sentido. A colocação dos problemas abarca os seguintes pressupostos: análise e delimitação da situação inicial; delineamento da situação final, em função de critérios de desejabilidade e factibilidade; a identificação de todos os problemas a serem resolvidos para permitir a passagem de (a) para (b); planejamento das ações correspondentes; execução e avaliação das ações.

d) O lugar da teoria: o projeto de pesquisaação precisa estar articulado dentro de uma determinada realidade com um quadro de referências teóricas que é adaptado de acordo com o setor em que se dá a pesquisa. As informações serão analisadas e interpretadas à luz de uma determinada teoria.

e) Hipóteses: apesar da falsa concepção de que na linha interpretativista de pesquisa não existem hipóteses, é chegado o momento de pensar com cuidado acerca desta proposição. É fundamental compreender as hipóteses como suposições formuladas pelo pesquisador a respeito de possíveis soluções para um problema colocado na pesquisa. Elas assumem um caráter de condutoras do pensamento e não são testadas.

f) Seminário: o seminário desempenha um papel coletivo de discussões e tomada de decisões acerca da investigação, além de coordenar as atividades e substituir as atas. As principais tarefas do seminário são: definir o tema e equacionar os problemas para os quais a pesquisa foi solicitada; elaborar a problemática na qual serão tratados os problemas e as correspondentes hipóteses da pesquisa; constituir os grupos de estudos e equipes de pesquisa; coordenar suas atividades; centralizar as informações provenientes das diversas fontes e grupos; elaborar as interpretações; buscar soluções e definir diretrizes de ação; acompanhar e avaliar as ações e divulgar os resultados pelos canais apropriados.

g) Campo de observação, amostragem e representatividade qualitativa: a pesquisaação pode abranger uma comunidade geograficamente concentrada e/ou espalhada. A questão da amostragem e da representatividade é fator discutível. Alguns excluem a amostra, outros recomendam o seu uso e uma terceira posição valoriza os critérios de representatividade qualitativa.

h) Coleta de dados: as principais técnicas utilizadas são as entrevistas coletivas e/ou individuais, os questionários convencionais, o estudo de arquivos, entre outros. Na seqüência, as informações coletadas pelos diversos grupos de observação e pesquisadores de campo são transferidas para o seminário central, onde são 
discutidas, analisadas e interpretadas em conjunto.

i) Aprendizagem: na pesquisa-ação tem-se a associação entre a capacidade de aprendizagem e o processo de investigação. Vale lembrar, que muitas vezes é possível entrever a colaboração entre os participantes apenas na perspectiva do pesquisador para com os pesquisados.

j) Saber formal e saber informal: partindo da suposição de que há diferentes formas de saber, os pesquisadores, num primeiro momento, são levados a descrever a situação ou o problema focalizado, buscando explicação e solução possíveis. Deve ocorrer, nessa fase, a comparação de temáticas a fim de mostrar as zonas de compatibilidades e incompatibilidades e, conseqüentemente, as estratégias de compreensão e intervenção.

I) Plano de ação: a elaboração do plano de ação consiste em definir com precisão: quem são os atores e/ou as unidades de intervenção? como se relacionam os atores e as instituições? quem toma as decisões? quais os objetivos a serem alcançados e os critérios de avaliação? como dar continuidade à ação na emergência de possíveis intercorrências? como assegurar a participação dos diferentes atores e como incorporar suas sugestões? como controlar o conjunto do processo e avaliar os resultados?

m) Divulgação externa: além de dar o retorno aos participantes da pesquisa, é importante que os resultados sejam divulgados em periódicos, eventos, congressos, conferências e outros, para que o conhecimento produzido seja validado e/ou refutado.

\section{CONSI DERAÇÕES FI NAIS}

O processo de investigação, apreensão da realidade, bem como o desencadeamento e a avaliação das ferramentas metodológicas qualitativas, requerem dialogicidade, conhecimento reflexivo e um compromisso com a realidade concreta, o que implica, em outras palavras, um reconhecimento efetivo do sujeito no objeto e um movimento dinâmico de ida das partes ao todo e vice-versa. É nessa perspectiva circular e dinâmica que a pesquisa-ação encontra ressonância e sustentação para a conquista de um novo espaço e/ou a conquista de um novo conhecimento no contexto da saúde/enfermagem.

A pesquisa-ação enquanto ferramenta metodológica realizada por meio do agir comunicativo e participativo, favorece o compartilhamento de saberes, além de tecer uma estrutura relacional de confiança e comprometimento com os sujeitos que integram a realidade a ser transformada. O objeto da pesquisa-ação, nesse caso, consiste em resolver ou, pelo menos, em esclarecer os problemas da situação observada. Há, durante o processo, um acompanhamento das decisões, das ações e de toda a atividade intencional dos atores da situação. Sob esse enfoque, a pesquisa não se limita a uma forma de ação, mas, visa aumentar o conhecimento dos pesquisadores e o nível de consciência das pessoas/grupos envolvidos.

Sendo assim, a pesquisa vai muito além de um simples levantamento de dados e/ou intervenções na prática. Para além das considerações já pontuadas, a pesquisa-ação agrega discussões e explicações e possibilita gerar um conhecimento descritivo e mais crítico acerca das situações vivenciadas nos espaços organizacionais e sociais. Possibilita, de outro modo, expressão e reflexão a respeito dos significados e sentimentos dos participantes e seus pares atribuídos ao processo de avaliação de desempenho.

A função da universidade não pode restringir-se ao ensino técnico-científico formal, mas também em oferecer oportunidades para aplicar tais conhecimentos na prática. O fazer na área da saúde/enfermagem envolve, por excelência, um agir interativo e intersubjetivo. Nessa perspectiva, a pesquisa-ação se constitui numa importante ferramenta metodológica pela possibilidade de agregar valores, sentimentos, ações e, por ampliar e estreitar a rede de interações entre sujeito-objeto e teoria-prática.

Em suma, a pesquisa-ação se constitui em uma importante ferramenta metodológica no contexto da saúde/enfermagem, pelo fato da mesma não sustentar-se em epistemologias positivistas e lineares, mas em abordagens que pressupõem a integração dialética entre o sujeito e sua existência, entre os fatos e valores, entre teoria e ação e, principalmente, entre pesquisador e pesquisado.

\section{REFERÊNCI AS}

1. Cunha PV. Resenhas - Metodologia da pesquisaação. In: Thiollent M. Metodologia da pesquisa-ação. São Paulo: Cortez-Autores Associados; 1986.

2. Caregnato RCA, Mutti R. Pesquisa qualitativa: análise de discurso versus análise de conteúdo. Texto contexto-enferm. 2006; 15(4):679-84.

3. Thiollent M. Metodologia da pesquisa-ação. São Paulo: Cortez; 1986.

4. Thiollent M. Pesquisa-ação nas organizações. São Paulo: Atlas; 1997.

5. Franco MAS. Pedagogia da pesquisa-ação. Educ. Pesqui. [Internet]. 2005 [cited 2009 jul 30]; 31(3):483-502. Available from: http://www.scielo. br/pdf/ep/v31n3/a11v31n3.pdf.

6. Haguette TMF. Metodologias qualitativas na sociologia. 9th ed. Petrópolis: Vozes; 2003.

7. Rolim KMC, Bezerra MGA, Moreira VTA, Maria FM. Mulheres em uma aula de hidroginástica: experenciando o interrelacionamento grupal. Revista Brasileira em Promoção da Saúde. 2004; 17(1):8-13. 
8. Lewin K. Teoria de campo em ciência social. São Paulo: Pioneira; 1965.

9. Feldman, A. Erzberger's dellemma: validity in action research and science teachers need to know. Science Education. 1994; 78(1): 83-101.

10. André, MEDA. Etnografia da prática escolar. Série Prática Pedagógica. Campinas: Papirus; 2000.

11. Pereira, EMA. Professor como pesquisador: o enfoque da pesquisa-ação na prática docente. In: Geraldi, CMG, Fiorentini, D, Pereira, EMA, org. Cartografias do trabalho docente: $\operatorname{professor}(a)$ pesquisador(a). Coleção Leituras no Brasil. Campinas: Mercado das Letras; 2001. p. 153-81.

12. Lewin, K. Problemas de dinâmica de grupo. São Paulo: Cultrix; 1946.

13. Barbier R. A pesquisa-ação. Brasília: Plano; 2002.

Artigo recebido em 23.10.07.

Aprovado para publicação em 27.02.09.

Artigo publicado em 30.09.09. 